\title{
Utilization of Waste Saw Dust from Wood Industry in Development of Glass Fiber Epoxy Resin Hybrid Green Composite Material
}

\author{
Mayank Agarwal ${ }^{1}$, Anurag Dixit ${ }^{2}$, Shashi Prakash Dwivedi ${ }^{3 *}$, Raghvendra Kumar Mishra ${ }^{4}$ \\ ${ }^{1}$ School of Engineering, Department of Mechanical Engineering, Gautam Buddha University, Greater Noida 201312, India \\ ${ }^{2}$ Department of Mechanical \& Automation Engineering, Govind Ballabh Pant Government Engineering College, New Delhi \\ 110020, India \\ ${ }^{3}$ G. L. Bajaj Institute of Technology \& Management, Greater Noida 201306, India \\ ${ }^{4}$ Department of Mechanical Engineering, Shri Mata Vaishno Devi University, Jammu \& Kashmir 182320, India
}

Corresponding Author Email: spdglb@gmail.com

https://doi.org/10.18280/acsm.430405

Received: 3 May 2019

Accepted: 17 July 2019

\section{Keywords:}

waste sawdust, green glass fibre composite, water absorption, soil degradation, acid corrosion test

\begin{abstract}
Sawdust or wood dust is a waste product of woodworking operations. The dust produces lots of environment pollution and is very harmful to the lungs. Effective utilization of this sawdust can resolve lots of environment pollution. The purpose of this study is to optimally utilize the waste sawdust from the wood industry thereby developing and characterizing hybrid green composite. In the present investigation, composite plates of glass fibre reinforced epoxy and glass fibre/sawdust reinforced epoxy were fabricated using hand lay-up technique and these plates were cured in a hot air oven for 8-10 hours at $60-70{ }^{\circ} \mathrm{C}$. The sawdust was first used as raw and then used by treating with $\mathrm{NaOH}$. The results showed that the mechanical properties of the composites on treatment with $\mathrm{NaOH}$ enhances in comparison to the untreated one. The flexural strength of a hybrid composite of $10 \%$ sawdust on treatment with $\mathrm{NaOH}$ exceeds that of glass fibre reinforced epoxy resin composite. The tensile strength also increases in the treatment of sawdust. The hardness of treated composites is far more superior to untreated. Water absorption is reduced in treated composites up to $20 \%$ sawdust weight proportion, thereafter it increases.
\end{abstract}

\section{INTRODUCTION}

A fibre-reinforced composite (FRC) is a composite building material that consists of three components: (i) the fibres as the discontinuous or dispersed phase, (ii) the matrix as the continuous phase, and (iii) the fine interphase region, also known as the interface. It is well acknowledged that most advanced fibre composites are stronger in tension than in compression. This behaviour of the composites is with the fact that the compressive strength of unidirectional composites is directed by micro buckling of fibres reinforced in the matrix [1-4].

Literature review reveals that work has been done on glass fibre reinforced epoxy composite, wood polymer composites and sawdust as filler in polypropylene, but very little work was carried out sawdust as secondary fibre with glass fibre reinforced epoxy [9-11]. Composite materials are classically used for the construction of buildings, bridges, and some of the structures like boat hulls, natatorium panels, motorcar bodies, shower stalls, bathtubs, storage tanks, cultivated marble sinks and countertops. The foremost advanced examples perform habitually on artificial satellite and craft in stern environments [5-8].

Sawdust is a waste product of woodworking operations such as sanding, drilling, routing, planning, milling and sawing [3]. Airborne sawdust and sawdust accumulations present several health and safety hazards. Wood dust becomes a potential health problem when the wood particles are inhaled inside the nose. However, the effective utilization of sawdust in the development of composite materials can resolve some environmental problem.

In the present investigation, unidirectional glass fibre/epoxy and hybridization of glass fibre with sawdust reinforced epoxy composites were fabricated. Tensile test, flexural test, hardness test, Charpy impact strength test, water absorption test, soil degradation test and corrosion test of the composite were performed to identify the effect of sawdust in glass fibre matrix based composite.

\section{MATERIALS AND METHODS}

\subsection{Matrix material}

In the context of fibre reinforced polymers (plastics), epoxy is used as the resin matrix to efficiently hold the Fibre in its place. It is compatible with all common reinforcing Fibres including Fibre glass, Carbon Fibre, aramid, and basalt. When compared with other traditional thermoset or thermoplastic resins, epoxy resins have distinct advantages, including low shrink during cure, very good moisture retention, excellent chemical resistance, good electrical properties, increased mechanical \& fatigue strengths, good impact resistant and it has long shelf life. 


\subsection{Fibre material}

\subsubsection{Glass fibre}

Glass Fibres are used since it provides the strength to the composite and is light in weight which reduces the overall weight of the composite. It also provides moisture resistance, dimensional stability, fire resistance and thermal conductivity. Here in present experimental work, firstly a pure synthetic fibre composite was fabricated by using glass fibre (E-glass) as reinforcement. Glass fabric WR 200 is used to fabricate unidirectional glass fibre/epoxy plates.

\subsubsection{Sawdust fibres}

Second Fibre used is sawdust to prepare hybrid composite of glass fibre and sawdust reinforced epoxy. Figure 1 shows the photograph of Soft Sawdust Fibres, Rough Sawdust Fibres and Treated Rough Sawdust Fibre. Sawdust was obtained from local industry. In this investigation, sawdust is used because of various advantages such as:

(1) Sawdust requires very less processing before using it as reinforcement.

(2) It is very easily available at very cheap or zero cost.

(3) Sawdust finds application in the conservation of meat and fish, hence do not decompose itself.

(4) This material is lightweight.

(5) It is accepted as environmentally friendly.

(6) It is an insulating material.

(7) It does not contain nor emit any toxic elements during fabrication of composite.

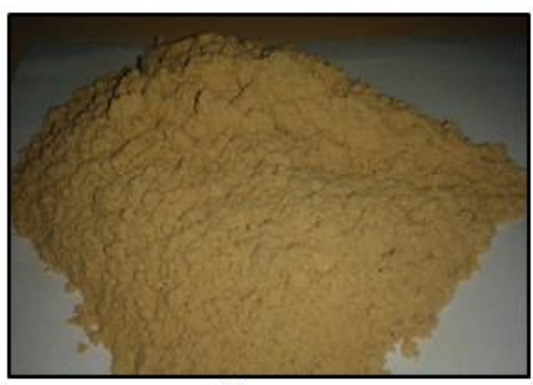

(a)

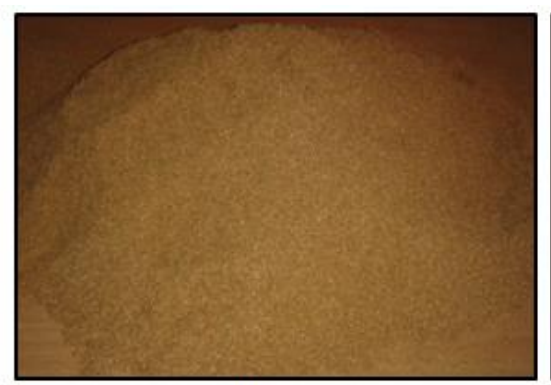

(b)

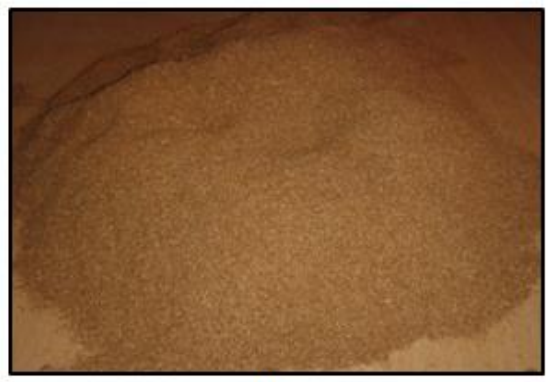

(c)

Figure 1. (a) Soft sawdust fibres, (b) Rough sawdust fibres, (c) Treated rough sawdust fibre

\subsection{Fabrication of the glass fibre composites}

All the composite plates were fabricated by maintaining ratios in proportion to weight. Hand lay-up technique was used in the fabrication process. It is less volume, labor intensive method suited particularly for massive elements, such as boat hulls. Hand lay-up is the simplest and oldest open moulding method of the composite fabrication processes. Proportions by weight percentage of different composite plates with sample designations are shown in Table 1.

Table 1. Proportion by weight percentage of different composite plates with sample designation

\begin{tabular}{|c|c|}
\hline \multicolumn{2}{|c|}{$\begin{array}{l}\text { Composition of GLASS FIBRE REINFORCED EPOXY } \\
\text { Composite }\end{array}$} \\
\hline Sample Designation & Composite \\
\hline D1 & $\mathrm{G} 40-\mathrm{E} 60$ \\
\hline \multicolumn{2}{|c|}{$\begin{array}{l}\text { Composition of Soft Sawdust \& Glass Fibre Reinforced Epoxy } \\
\text { Hybrid Composite }\end{array}$} \\
\hline $\mathrm{D} 2$ & $\mathrm{G} 30-\mathrm{S} 10-\mathrm{E} 60$ \\
\hline D3 & $\mathrm{G} 20-\mathrm{S} 20-\mathrm{E} 60$ \\
\hline D4 & $\mathrm{G} 10-\mathrm{S} 30-\mathrm{E} 60$ \\
\hline D5 & G00 - S40 - E60 \\
\hline \multicolumn{2}{|c|}{$\begin{array}{l}\text { Composition of Rough Sawdust Fibre \& Glass Fibre Reinforcec } \\
\text { Epoxy Hybrid Composite }\end{array}$} \\
\hline D6 & $\mathrm{G} 30-\mathrm{S} 10-\mathrm{E} 60$ \\
\hline D7 & $\mathrm{G} 20-\mathrm{S} 20-\mathrm{E} 60$ \\
\hline D8 & $\mathrm{G} 10-\mathrm{S} 30-\mathrm{E} 60$ \\
\hline D9 & G00 - S40 - E60 \\
\hline \multicolumn{2}{|c|}{$\begin{array}{l}\text { Composition of Treated Rough Sawdust Fibre \& Glass Fibre } \\
\text { Reinforced Epoxy Hybrid Composite }\end{array}$} \\
\hline D10 & $\mathrm{G} 30-\mathrm{S} 10-\mathrm{E} 60$ \\
\hline D11 & $\mathrm{G} 20-\mathrm{S} 20-\mathrm{E} 60$ \\
\hline D12 & $\mathrm{G} 10-\mathrm{S} 30-\mathrm{E} 60$ \\
\hline D13 & G00 - S40 - E60 \\
\hline
\end{tabular}

\subsection{Water absorption test}

Water absorption test was carried out to determine the amount of water that is absorbed under specified conditions. Moisture absorption study was performed according to the ASTM D570 standards. The initial weights of the samples were taken, and then after the samples were immersed into distilled water. After 24 hours, the samples were taken out from the water and surface moisture was removed. Subsequently, the samples were reweighed to the nearest of $0.001 \mathrm{mg}$. The samples were regularly weighed over the interval 24, 48, 72, 96, 120, 144, 168, 192 hours respectively. The weight gain in the percentage of the samples was measured at regular time intervals. The percentage change in weight or the weight of water gained is estimated as mentioned in Eq. No 1:

$$
W \%=\left(\frac{W_{t}-W_{0}}{W_{0}}\right) * 100
$$

where, $\mathrm{W}_{\mathrm{t}}=$ weight of sample at time $\mathrm{t}, \mathrm{W}_{0}=$ initial weight of the sample, and $\mathrm{W}=$ weight of water absorbed.

\subsection{Soil degradation test}

The soil degradability test was carried out for assessment of the effect of natural agents like soil and moisture on the performance of the hybrid composite. The initial weight of the composite sample was taken and then the composite samples were buried in the soil (having at least $25 \%$ moisture) for different periods. After a certain period i.e. after 4 weeks samples were withdrawn carefully, cleaned and then the final weight was measured. The difference between the initial and final weights gives the result of the degradability of the composite. 


\section{RESULTS AND DISCUSSION}

\subsection{Tensile strength analysis}

Figure 2 shows the tensile strength analysis of various sample designation. The experimental results revealed that Glass Fibre-Epoxy composite has maximum tensile strength (173 MPa) due to brittle nature. It is noticed that $10 \%$ soft sawdust Fibre and $30 \%$ Glass Fibre - Epoxy hybrid composite has maximum tensile strength with the value of $62.0 \mathrm{MPa}$ in comparison to all other soft sawdust Fibre composites. The strength decreases with increase in sawdust Fibre content. The weakest is G00-S40 in which no glass Fibre is present and has a value of $2.0 \mathrm{MPa}$. From the experimental results, it is noticed that rough sawdust Fibre \& Glass Fibre reinforced Epoxy hybrid composite has different behaviour on the treatment of sawdust Fibres with $\mathrm{NaOH}$. The untreated composites have a less tensile strength in comparison to the treated ones. The strength decreases with increase in the sawdust Fibre content due to low load-bearing capacity. The maximum tensile strength is shown by G30S10-E60 in untreated composite with the value of $44.7 \mathrm{MPa}$ whereas upon treatment this value reached to $91 \mathrm{MPa}$.

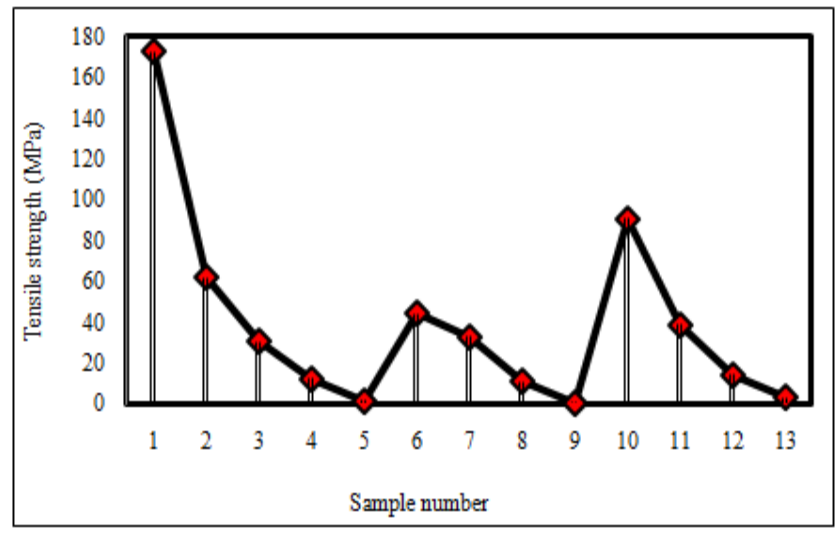

Figure 2. Tensile strength analysis of various sample designations

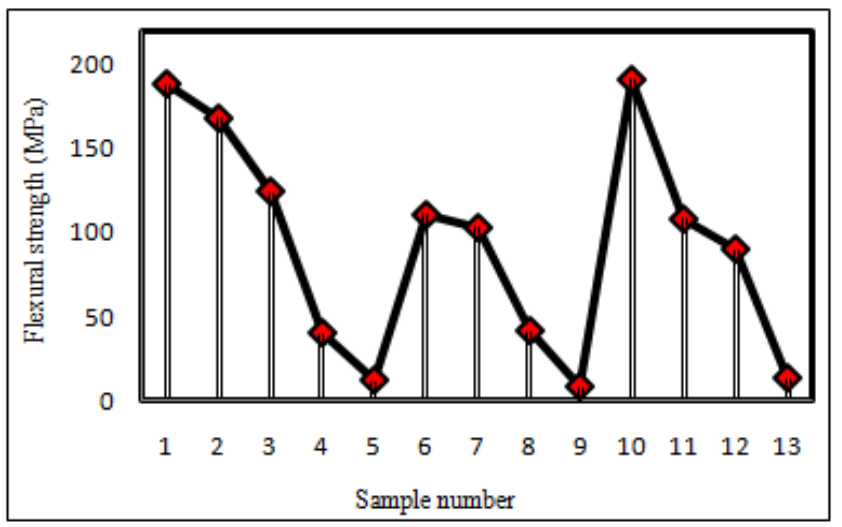

Figure 3. Flexural strength analysis of various sample designations

\subsection{Flexural test analysis}

The flexural strength of Glass Fibre-Epoxy Composite is $188 \mathrm{MPa}$ which shows it can resist maximum load before deformation. The Hybrid Composite of soft sawdust Fibre showed that the Flexural Strength decreases with increase in Sawdust Fibre content with G30-S10-E60 having a maximum strength of $168.4 \mathrm{MPa}$ and G00-S40-E60 showing the least Strength. The flexural Strengths obtained experimentally for Hybrid Composites shows that the Strength of Treated sawdust Fibre is more than the untreated as shown in Figure 3.

The maximum Strength shown by G30-S10-E60 among untreated Hybrid composites is $110.5 \mathrm{MPa}$ which increased to $191 \mathrm{MPa}$ after $\mathrm{NaOH}$ Treatment which is even superior to that of Glass Fibre Reinforced Epoxy Composite (G40-E60). The least Strength is with Sawdust reinforced Epoxy Composite with the value of $8.2 \mathrm{MPa}$ which upon treatment reaches to $13.1 \mathrm{MPa}$.

\subsection{Hardness analysis}

Two types of hardness tests were conducted on the specimens from every composite plate:

(1) Shore D Test

(2) Vickers Hardness Test

\subsubsection{Shore D test}

Table 2 shows the comparison of Shore D Hardness of all the samples. The hardness of Hybrid Composite decreases with the increase in Sawdust Fibre Content because of its porous nature. G30-S10-E60 has highest Shore D hardness among all and on treatment with $\mathrm{NaOH}$, its hardness increases to even more than that of G40-E60 Composite. $\mathrm{NaOH}$ treatment also increased the hardness of every composite plate. The highest value of Hardness is shown by Treated G30-S10-E60 that is 92-94 whereas the lowest value of hardness is shown by untreated G00-S40-E60 that is 70-72.

Table 2. Shore D test of different composite plates with sample designation

\begin{tabular}{|c|c|c|}
\hline $\begin{array}{c}\text { Sample } \\
\text { designation }\end{array}$ & Composite & $\begin{array}{l}\text { Shore } \mathrm{D} \text { hardness } \\
\text { test value }\end{array}$ \\
\hline D1 & G40 - E60 & $88-90$ \\
\hline \multicolumn{3}{|c|}{$\begin{array}{l}\text { Composition of rough sawdust fibre \& } \\
\text { glass fibre reinforced epoxy hybrid } \\
\text { composite }\end{array}$} \\
\hline D6 & $\mathrm{G} 30-\mathrm{S} 10-\mathrm{E} 60$ & $87-89$ \\
\hline D7 & G20 - S20 - E60 & $84-86$ \\
\hline D8 & G10 - S30 - E60 & $75-77$ \\
\hline D9 & $\mathrm{G} 00-\mathrm{S} 40-\mathrm{E} 60$ & $70-72$ \\
\hline \multicolumn{3}{|c|}{$\begin{array}{l}\text { Composition of treated rough sawdust } \\
\text { fibre \& glass fibre reinforced epoxy } \\
\text { hybrid composite }\end{array}$} \\
\hline D10 & $\mathrm{G} 30-\mathrm{S} 10-\mathrm{E} 60$ & $92-94$ \\
\hline D11 & $\mathrm{G} 20-\mathrm{S} 20-\mathrm{E} 60$ & $87-89$ \\
\hline D12 & $\mathrm{G} 10-\mathrm{S} 30-\mathrm{E} 60$ & $80-82$ \\
\hline D13 & G00 - S40 - E60 & $74-76$ \\
\hline
\end{tabular}

\subsubsection{Vickers hardness test}

Vickers hardness as observed experimentally of Hybrid Composite shows that G30-S10-E60 has the highest hardness among all and on treatment with $\mathrm{NaOH}$, its hardness increases to even more than that of G40-E60 Composite. $\mathrm{NaOH}$ treatment also increased the hardness of every composite plate. Vickers hardness analysis of various sample designations is shown in Figure 4. 


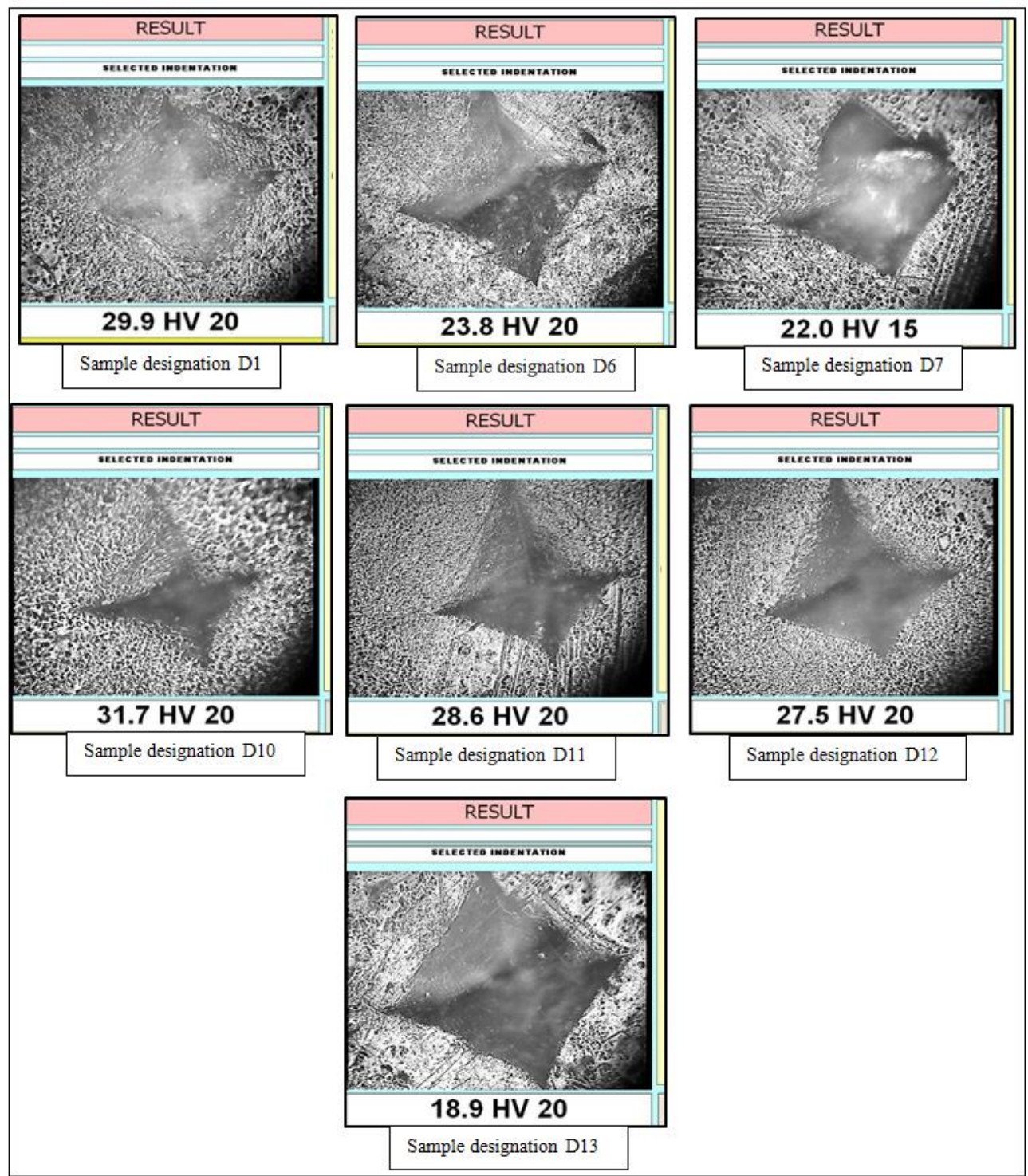

Figure 4. Vickers hardness analysis of various sample designations

\subsection{Charpy impact strength analysis}

Table 3 shows the impact strength of all sample designation samples. The Impact Strength Test was performed on the Composites and the result showed that the Impact Strength is the maximum of G40-E60 composite. The maximum strength in Hybrid Composite was shown by G30S10-E60 with the value of $16.1 \mathrm{KJ} / \mathrm{m}^{2}$ which upon treatment with $\mathrm{NaOH}$ reached to $22 \mathrm{KJ} / \mathrm{m}^{2}$. The impact strength of the Sawdust and Glass Fibre reinforced Epoxy Hybrid Composite improved by the treatment of Sawdust Fibres with $\mathrm{NaOH}$.

Table 3. Results of impact test of composites

\begin{tabular}{|c|c|}
\hline Sample Designation & Charpy Impact Strength $\left(\mathbf{K J} / \mathbf{m}^{\mathbf{2}}\right)$ \\
\hline D1 & 39.5 \\
\hline D6 & 16.1 \\
\hline D7 & 16.8 \\
\hline D8 & 14.6 \\
\hline D9 & 1.8 \\
\hline D10 & 22 \\
\hline D11 & 17 \\
\hline D12 & 16.8 \\
\hline D13 & 4.0 \\
\hline
\end{tabular}

\subsection{Water absorption analysis}

The samples from each composite plate are kept in distilled water for 15 days or 360 hours and significant changes are observed after every 2 days or 48 hours. It is noticed that weight per cent of Glass Fibre Epoxy Composite increase rapidly for the first 7 days and after that, for the next 7 days, there is not any significant increase in the weight percentage as shown in Figure 5. After 12 days the \% increase in weight has not much difference between them. The amount of water absorbed becomes almost constant after a certain period. The maximum percentage of weight increased as observed is $4.76 \%$. Zoom stereo microscope of water test specimen on G40-E60 composite is shown in Figure 6 (a).

These free hydroxyl groups come in contact with water and form hydrogen bonding, which results in weight gain in the composites. But the \% increase in weight of untreated composites was more than the treated ones in $10 \%$ and $20 \%$ sawdust composites. This implies that the chemical treatment had removed some $\mathrm{OH}$ groups inside the cellulose thus reducing the number of free $\mathrm{OH}$ groups. Reason for less water content of the treated sawdust composites is good interaction between the matrix and treated sawdust that resulted in void minimization in the resultant composites. 


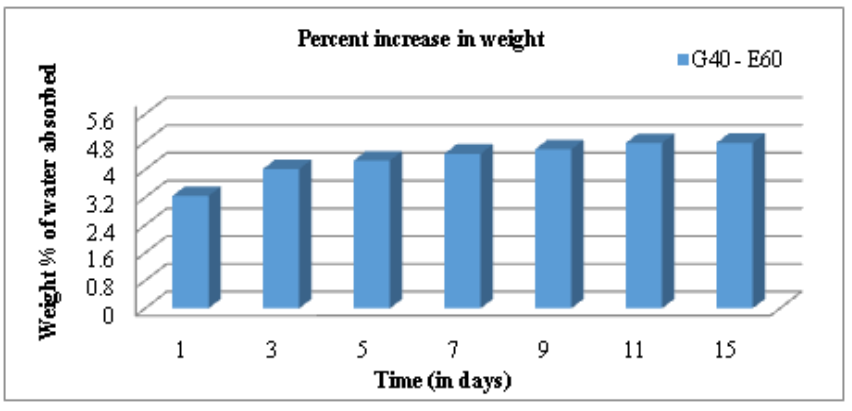

Figure 5. Percent increase in weight of G40-E60 (sample designation D1) in 15 days

The water absorption test on hybrid composites shows the increase in weight of the samples due to the hydrophilic nature of sawdust as shown in Figure 7. Zoom stereo microscopy on G00-S40-E60 Composite, on untreated hybrid composite, on the treated hybrid composite is shown in Figure 6(b), Figure 6(c) and Figure 6(d) respectively. When the content of sawdust increases in the composite, the number of free $\mathrm{OH}$ groups increases from the cellulose and hemicellulose inside the fibre. This increase free $\mathrm{OH}$ responsible for an increase in the water absorption of the composite.

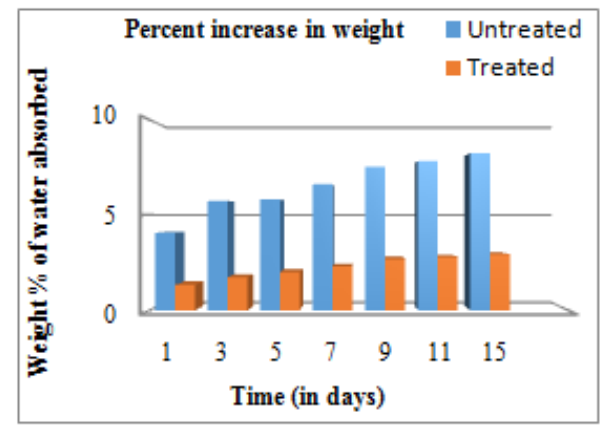

(a)

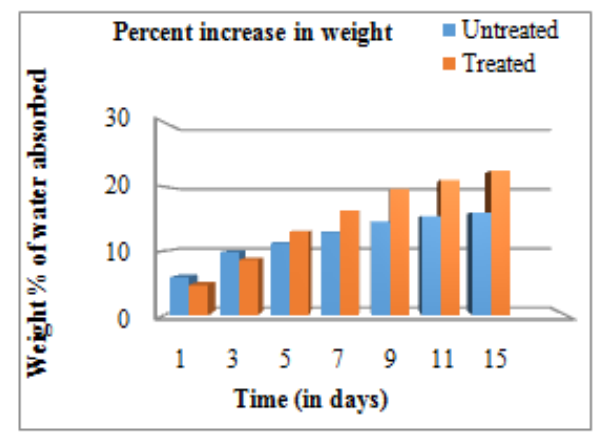

(c)

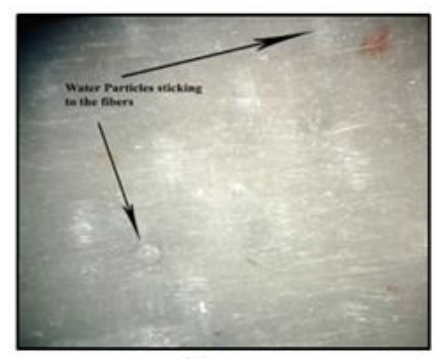

(a)

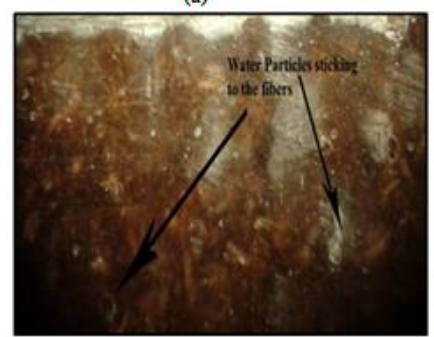

(c)

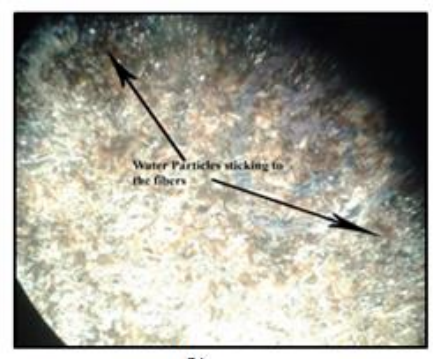

(b)

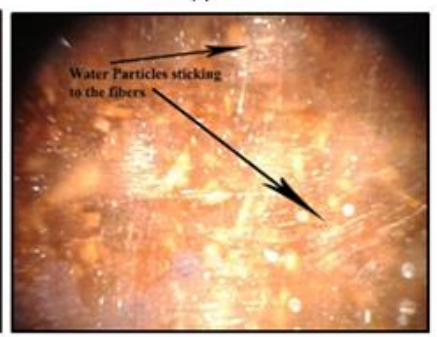

(d)

Figure 6. Zoom stereo microscopy of water test specimen: (a) Water absorption test on G40-E60 composite, (b) Water absorption test on G00-S40-E60 composite, (c) Water absorption test on untreated hybrid composite, (d) Water absorption test on treated hybrid composite

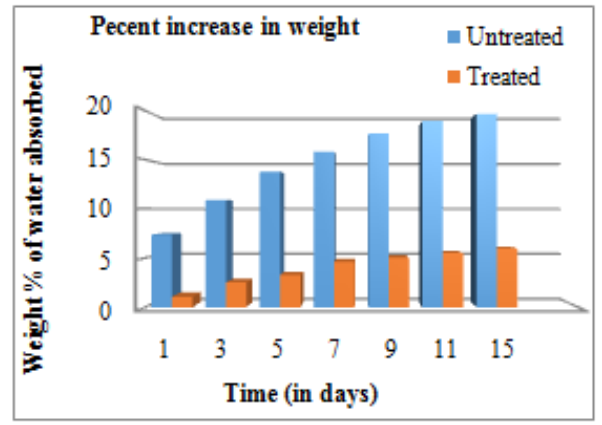

(b)

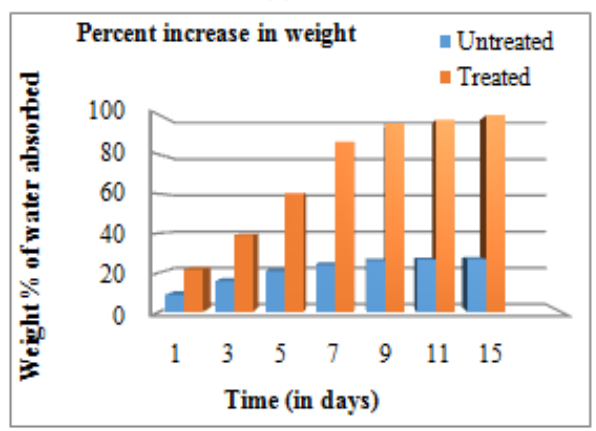

(d)

Figure 7. (a) Increase in weight of G30-S10, (b) Increase in weight of G20-S20, (c) Increase in weight of G10-S30, (d) Increase in weight of G00-S40

\subsection{Soil degradation analysis}

The samples were buried in the soil for one month and the effects of soil on the samples were noticed at regular intervals. The zoom stereo microscopy test (Figure 8) was also done on the samples to observe the erosion of the surface of composite by the soil. The soil used for degradation test is having $25 \%$ moisture in it. This test is performed to check for the adaptability of the composite in a moist soil environment. When G40-E60 composite buried under the soil, the weight of the sample continuously increases over some time as shown in Figure 9.

In Glass Fibre Epoxy Composite initially there is an increase in weight, but after 3 weeks the weight becomes almost constant as shown in Figure 10. The treated G20-S20E60 composite shows less increase in weight than untreated whereas in rest of the samples weight \% of treated is more than untreated. In G10-S30 and G00-S40 initially, weight \% is less in treated but after 1.5 weeks it increases rapidly than untreated composites. The maximum deterioration was shown by treated G00-S40 composite with a value of $23.4 \%$. 

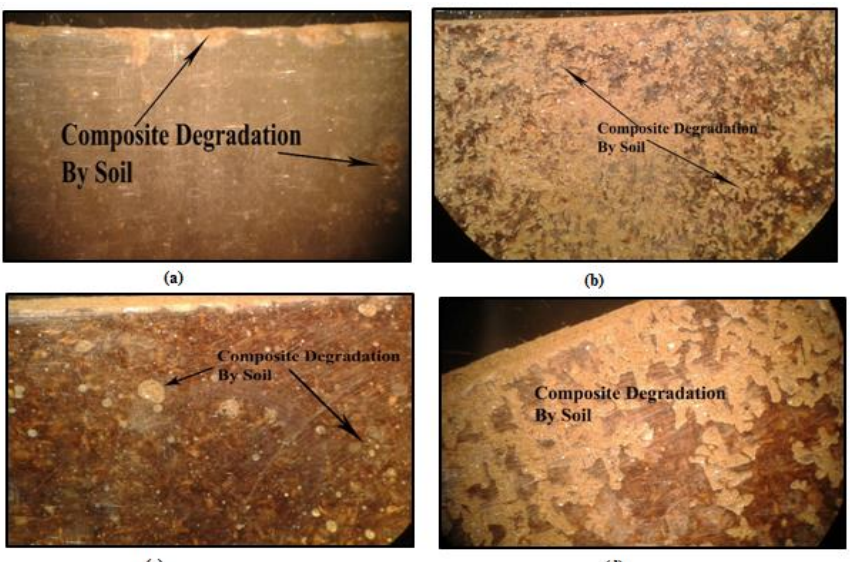

Figure 8. Zoom stereo microscopy of soil degradation test on (a) G40-E60 composite, (b) G00-S40-E60 composite, (c) Untreated hybrid composite, (d) Treated hybrid composite

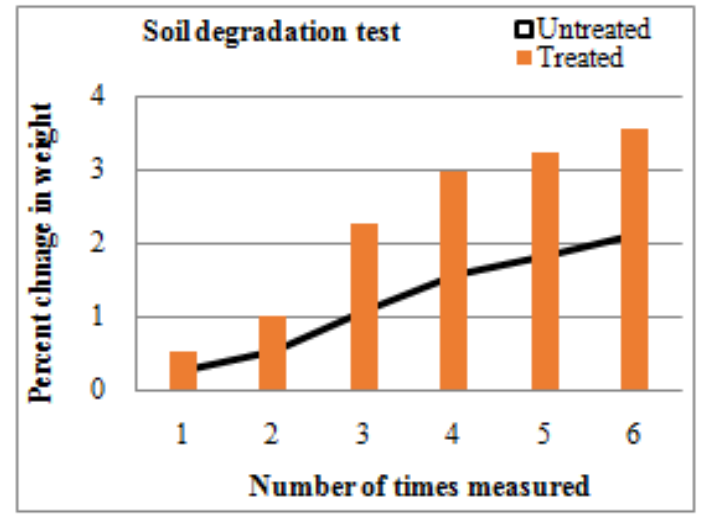

(a)

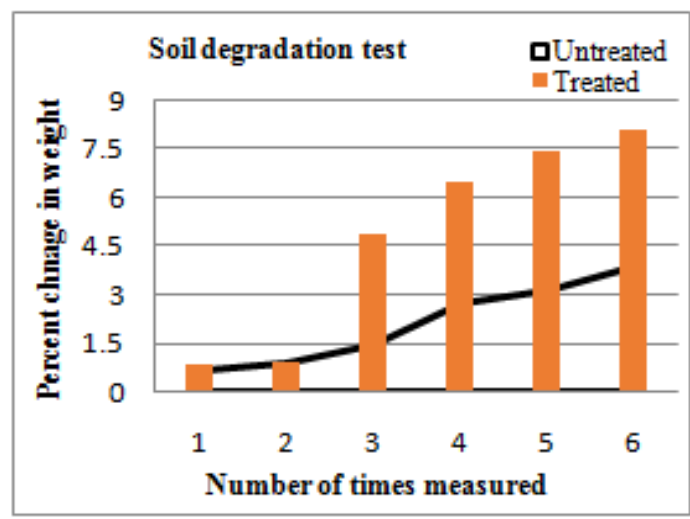

(c)

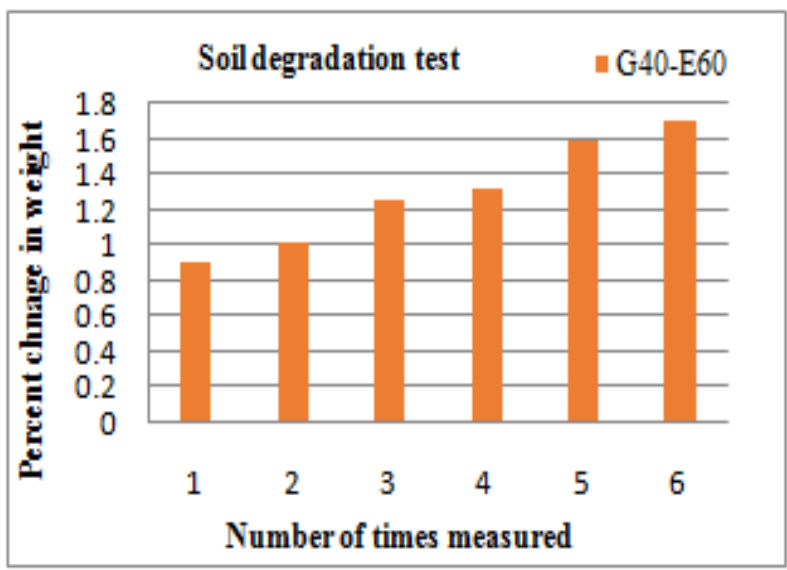

Figure 9. Percent change in weight of G40-E60 (sample designation D1) due to soil degradation

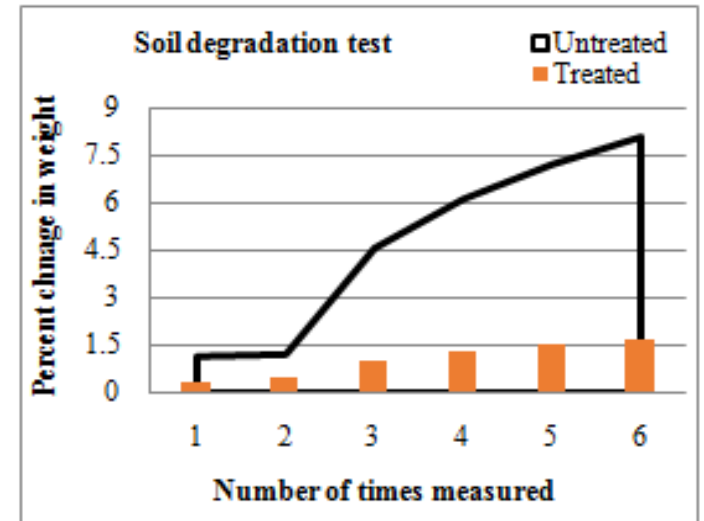

(b)

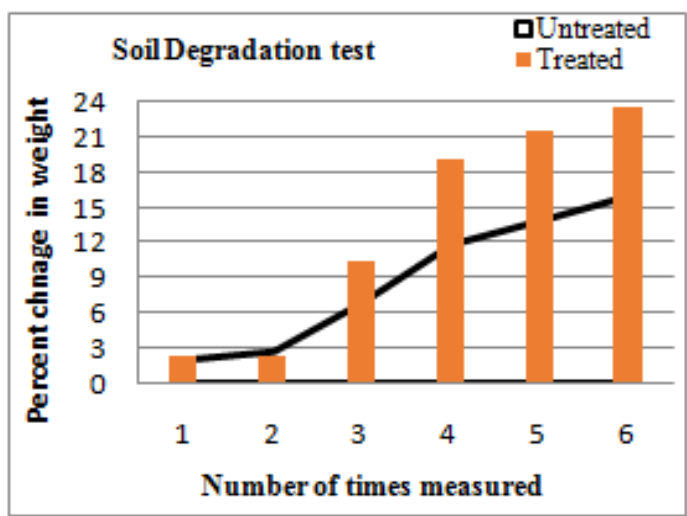

(d)

Figure 10. Soil Degradation Test: (a) \% change in weight of G30-S10, (b) \% change in weight of G20-S20, (c) \% change in weight of G10-S30, (d) \% change in weight of G00-S40

\subsection{Acid corrosion analysis}

The samples from every composite were kept in $50 \%$ Sulphuric Acid for 1 week and weighed every day to observe the changes that occur due to acid corrosion. The zoom stereo microscopy (Figure 11) was also done to observe the surface corrosion occurred by acid on the composites. Initially, there was an increase in the weight for 2-3 days, and then due to corrosion, there is a decrease in weight in the samples. This Fibres of the composite. The surfaces of the composites were corroded in the acid environment. This affects the strength of the composite by changing shape and bonding strength of the test is necessary to study the changes in shape, debonding or loss of strength in composites. In Glass Fibre composite due to the acid corrosion, initially there is an increase in the weight and then it reduces with time which shows the extent of corrosion. In treated hybrid composites, initially the weight increases rapidly due to the presence of $\mathrm{NaOH}$ (a base) and then there is a decrease in weight $\%$ due to the reaction between acid and base. The presence of the acid environment affects the interfacial adhesion of the matrix and reinforced matrix and Fibres. Acid corrosion behaviour of glass fibres are shown in Figure 12 and Figure 13 respectively. 

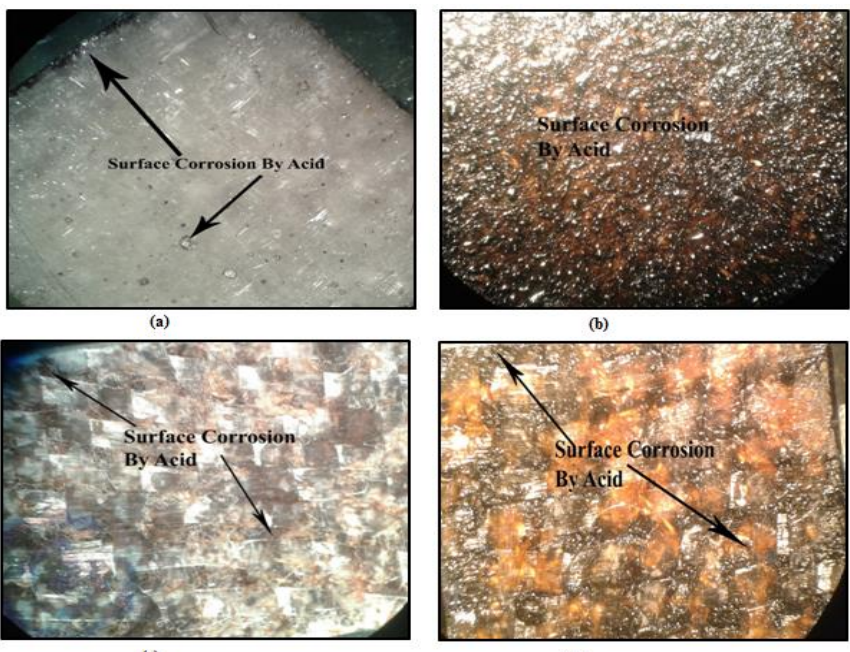

Figure 11. Zoom stereo microscopy of acid corrosion test on (a) G40-E60 composite, (b) G00-S40-E60 composite, (c) Untreated hybrid composite, (d) Treated hybrid composite

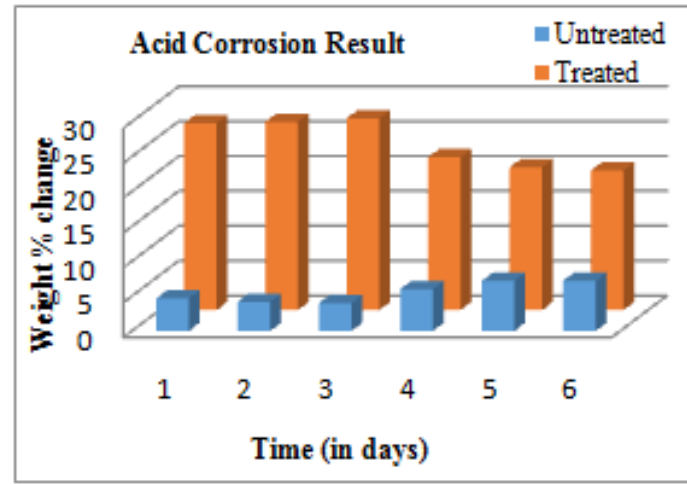

(a)

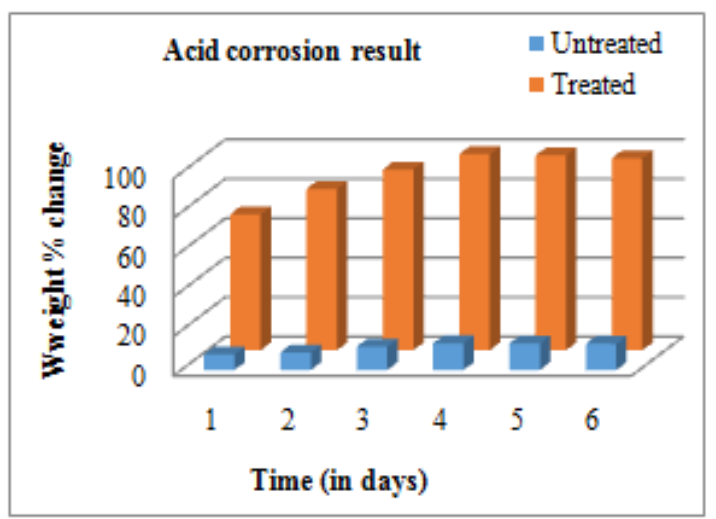

(c)

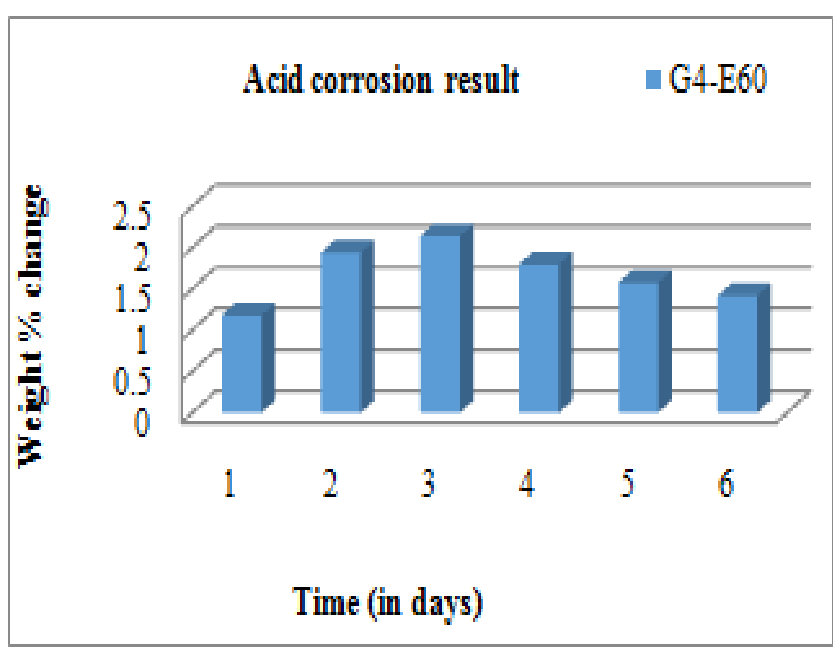

Figure 12. Percent change in weight of G40-E60 (sample designation D1) due to acid corrosion

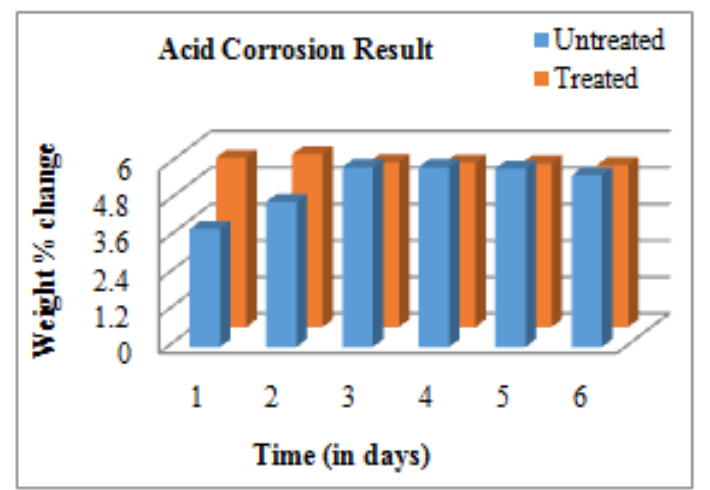

(b)

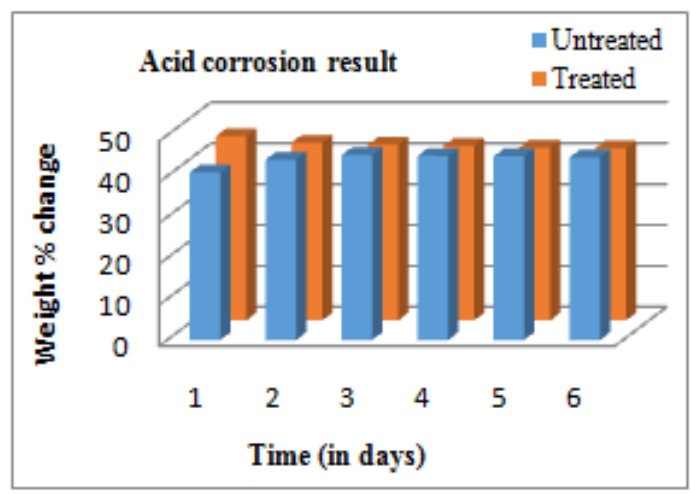

(d)

Figure 13. Acid corrosion analysis; (a) \% change in weight of G30-S10; (b) \% change in weight of G20-S20; (c) \% change in weight of G10-S30, (d) \% change in weight of G00-S40

\subsection{Surface morphology}

The specimens of the tensile fractured sample were used for observing surface morphology. Morphology studies revealed the adhesion between Fibre and matrix. Figure 14 shows the SEM micrographs of the tensile fractured surface of Glass Fibre-Reinforced Epoxy composite specimens. The interaction between epoxy and glass fibres has been shown in Figure 14. The composite shown in Figure 15 was developed using untreated sawdust as the Secondary fibre which produces poor interface adhesion. Whereas when Treated sawdust is used in Figure 16, the adhesion becomes strong which indicates wetting is good and the interface is strong which is clear from the surface of fibres where traces of epoxy and sawdust are found. The less fibre and matrix adhesion are clear from Figure 15 (b) in which the fibre surfaces are clean and little matrix adhesion on the fibre. But in Figure 16 (b) it is clear that good adhesion is present with the matrix traces sticking to the surface of the glass fibre. The fibre pulls out and delamination are the major features of failure in the composites. In the treated composites, little fibre pulls out was observed which shows the efficiency of the modified fibres to form strong adhesion. Also, the fibres on the fracture surface are orientated in the flowing direction 
of moulding. This shows that composites have a higher degree of fibre orientation under the stress resulting in higher fibre efficiency factor and hence higher mechanical strength.
The degree of fibre pull out and crack deflection in the composites are shown by the glass fibres protruding from the composite.

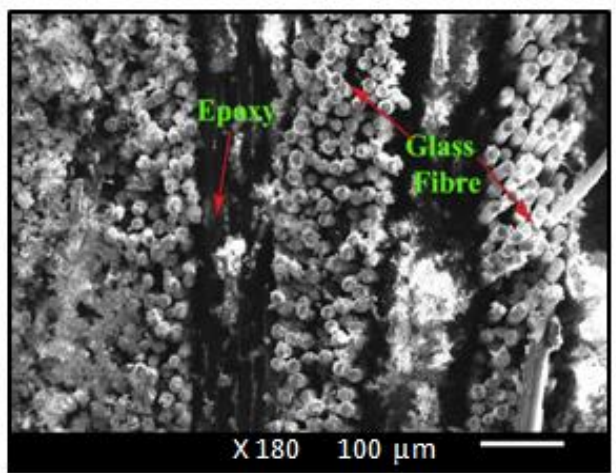

(a)

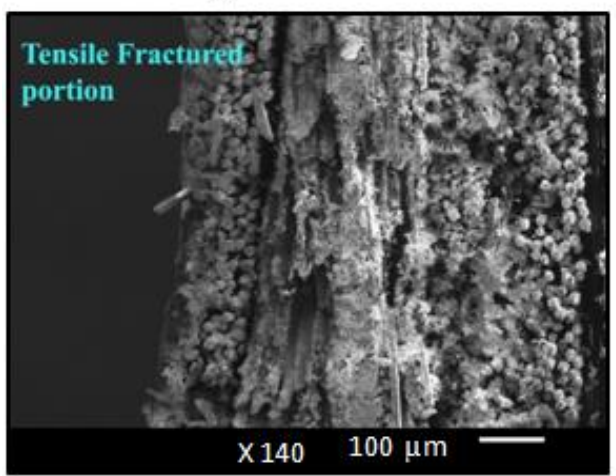

(c)

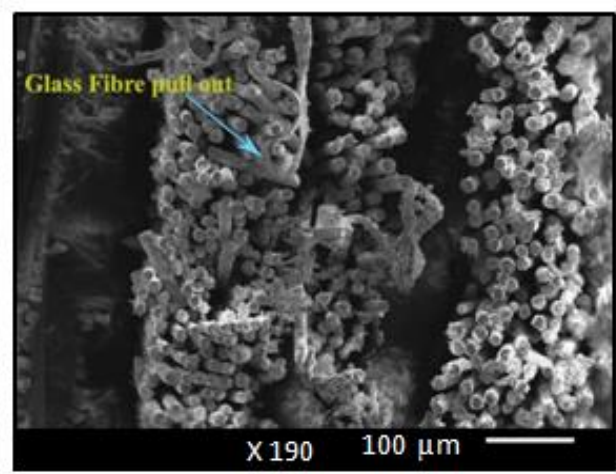

(b)

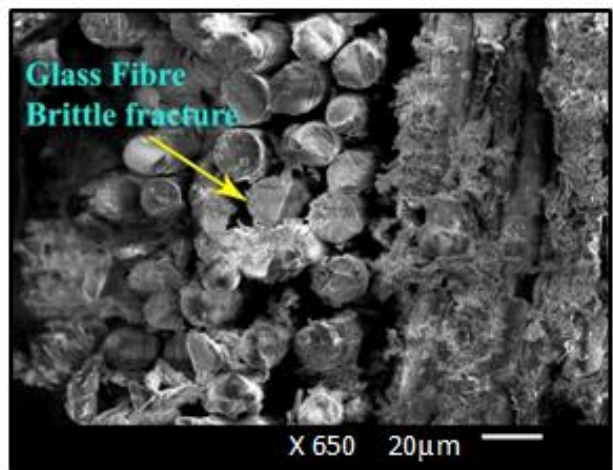

(d)

Figure 14. Morphologies of the glass fibre reinforced epoxy composite (G40-E60)

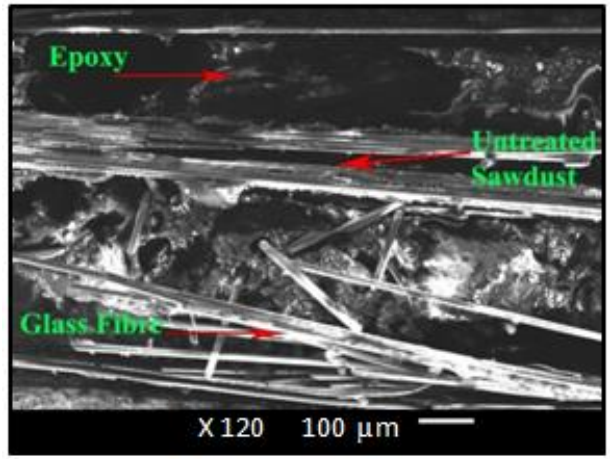

(a)

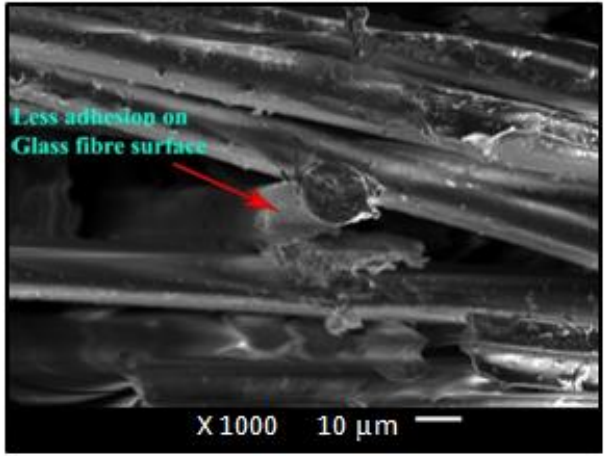

(b)

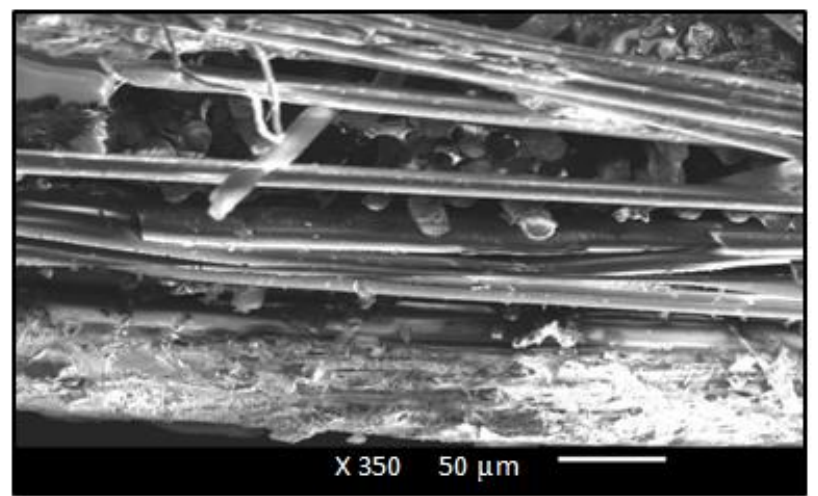

(c)

Figure 15. Morphologies of untreated sawdust and glass fibre reinforced epoxy composite (G30-S10-E60) 


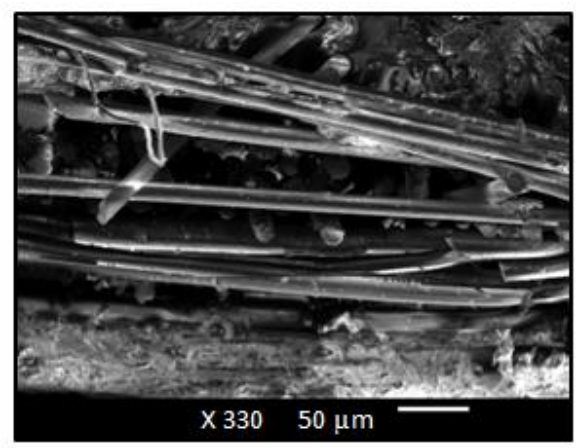

(a)

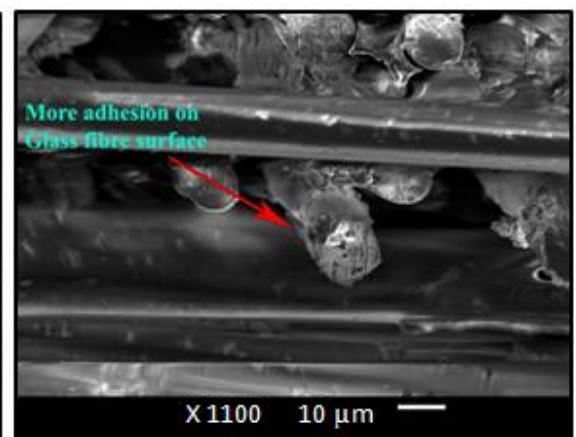

(b)

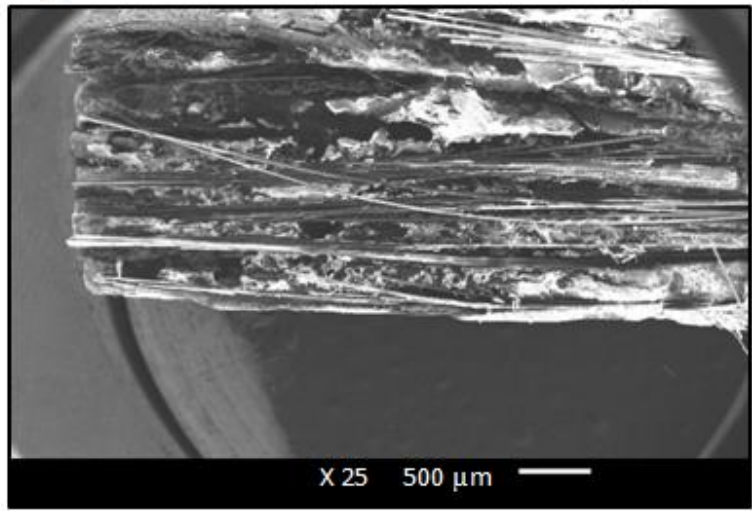

(c)

Figure 16. Morphologies of treated sawdust and glass fibre reinforced epoxy composite (G30-S10-E60)

\section{CONCLUSIONS}

From the results of the experiments, the following conclusions were drawn:

(1) From the Tensile Test it can be concluded that on decreasing proportion of Glass fibre or increasing proportion of sawdust, Tensile strength decreases of both soft and rough sawdust. But on the treatment of the sawdust fibres with $\mathrm{NaOH}$, there is a considerable increase in the Tensile Strength in every composite due to strong interfacial adhesion.

(2) From the Flexural test it is concluded that on decreasing proportion of Glass fibre or increasing proportion of sawdust, Flexural strength decreases of both soft and rough sawdust. But on Treatment with $\mathrm{NaOH}$, there is an increase in Flexural strength in every sample. Even in composite G30-S10-E60, the increase is so much that it exceeds the value of G40-E60 (Glass fibre reinforced Epoxy Composite). This shows that Inter-laminar shear strength was much better of treated hybrid Composites which means strong bonding between matrix and fibres.

(3) Conclusions drawn from the Hardness test are that with the decrease in Glass fibre content, the hardness of the sample decreases. The $\mathrm{NaOH}$ treatment shows that composite G30-S10-E60 has maximum hardness among all, even more than G40-E60. The result is verified by two hardness tests on the composites i.e. Shore D and Vickers Hardness Test. This shows that strong bonding resists any kind of indentation.

(4) Charpy Impact test concludes that the notched specimen of Glass fibre and epoxy has maximum impact strength. On increasing the sawdust fibre proportion the impact strength decreases of the composite.

(5) For the water absorption test it was observed that in G40-E60, the water absorption increased even though glass fibre does not show affinity towards water. This was the result of capillary action between the fibre bundles of glass fibre. For the hybrid composites, it is concluded that increasing sawdust proportion increases the water absorption percentage. Treatment of sawdust shows less water absorption than raw sawdust up to $20 \%$ but from $30 \%$ to $40 \%$ it shows more water absorption than raw sawdust.

(6) The results of soil degradation test assisted in concluding that Glass fibre reinforced Epoxy composite and sawdust/Glass fibre reinforced epoxy Hybrid composites show non-biodegradable nature under the soil but biodeterioration due to which surface erosion occurs but the loss in weight does not occur. Instead, there is an increase in weight because moisture was absorbed from the soil by the composites. These composites can find application in such an environment as it is non-bio degradable but the microbiological deterioration takes place in all the samples, leading to decay of the mechanical performance of the composites. The deterioration is maximum in treated G00S40-E60 with the value of $23.32 \%$.

(7) Acid corrosion test concludes that initially there is an increase in weight of the samples due to absorption of acid in the composite, then there is a slight decrease in weight due to little corrosion. The maximum corrosion occurs in treated G00-S40-E60 in which weight \% reduces from $45.36 \%$ to $40 \%$.

(8) Surface Morphology of the composites concludes that at the fracture points glass fibre shows brittle behaviour, epoxy remains on its place and glass fibre pulls out producing cracks, untreated hybrid composites show less interfacial adhesion and treated hybrid composites have comparatively higher interfacial adhesion, hence strong bonding.

Further, it is recommended that the application of natural 
fibre as a reinforcement in the green composite may result in much economical and eco-friendly solution for automotive and other industries.

\section{REFERENCES}

[1] Cho, J., Chen, J.Y., Daniel, I.M. (2007). Mechanical enhancement of carbon fiber/epoxy composites by graphite nano platelet reinforcement. Scripta Materialia, 56(8):

685-688.

https://doi.org/10.1016/j.scriptamat.2006.12.038

[2] Shinichi, S., Yong, C., Isao, F. (2005). Press forming of short natural-fiber reinforced biodegradable resin: Effects of fiber volume and length on flexural properties. Polymer Testing, 24(8): 1005-1011. https://doi.org/10.1016/j.polymertesting.2005.07.012

[3] Mateusz, S., Marek, M., Maciej, B., Ewa, G. (2015). Mechanical properties of sawdust and woodchips. Fuel, 159:

900-908 https://doi.org/10.1016/j.fuel.2015.07.044

[4] Sombatsompopand, N., Chaochanchaikul, K. (2004). Effect of moisture content on mechanical properties, thermal and structural stability and extrudate texture of poly (vinyl chloride)/wood sawdust composites. Polymer International, 53(9): 1210-1218. https://doi.org/10.1002/pi.1535

[5] Maries, I., Abderrahim, B., Umadevi, L., Laurent, I.L., Sabu, T. (2006). Thermophysical properties of natural fiber reinforced polyester composites. Compos Sci Technol, 66(15): $2719-2725$ https://doi.org/10.1016/j.compscitech.2006.03.007
[6] Guohua, W., Bharat, B., Peter, M.T. (2005). Nanochemical characterization of human hair using nanoindentation and SEM. Ultramicroscopy, 105(1-4): 248-66. https://doi.org/10.1016/j.ultramic.2005.06.033

[7] Geethamma, V.G., Kalaprasad, G., Gabriel, G., Sabu, T. (2005). Dynamic mechanical behavior of short coir fiber reinforced natural rubber composites. Composites Part A: Applied Science and Manufacturing, 36(11): 1499-506.

https://doi.org/10.1016/j.compositesa.2005.03.004

[8] Hammami, M., Mahi, A.E., Karra, C., Haddar, M. (2016). Nonlinear behaviour of glass fibre reinforced composites with delamination. Composites Part B: Engineering, 92: 350-359. https://doi.org/10.1016/j.compositesb.2016.02.031

[9] Fakhrul, T., Islam, M.A. (2013). Degradation behaviour of natural fiber reinforced polymer matrix composites. Procedia Engineering, 56: 795-800. https://doi.org/10.1016/j.proeng.2013.03.198

[10] Sombatsompop, N., Chaochanchaikul, K. (2004). Effect of moisture content on mechanical properties, thermal and structural stability and extrudate texture of poly (vinyl chloride)/wood sawdust composites. Polymer International, 53(9): 1210-1218. https://doi.org/10.1002/pi.1535

[11] Arivukkarasan, S., Dhanalakshmi, V., Stalin, B., Ravichandran, M. (2018). Mechanical and tribological behaviour of tungsten carbide reinforced aluminum LM4 matrix composites. Particulate Science and Technology, 36(8): 967-973. https://doi.org/10.1080/02726351.2017.1331285 